


\title{
Curatorial Practice as Production of Visual and Spatial Knowledge Panelists Respond
}

\author{
Alison Langmead, Dan Byers, and Cynthia Morton
}

\begin{abstract}
Three participants in the panel "Curatorial Practice as Production of Visual and Spatial Knowledge" reflect upon the ideas raised in their discussion about curating, both in their respective fields and as a general practice. The panel was a part of Debating Visual Knowledge, a symposium organized by graduate students in Information Science and History of Art and Architecture at the University of Pittsburgh, October 3-5, 2014. A transcription of the panel is available in this issue.
\end{abstract}

\section{About the Author}

Dr. Alison Langmead is the director of the Visual Media Workshop in the Department of History of Art and Architecture and Assistant Professor in the School of Information Scienes at the University of Pittsburgh.

Dan Byers is senior curator at the Institute of Contemporray Art, Boston. At the time of the discussion, he was Richard Armstrong Curator of Contemporary Art at the Carnegie Museum of Art.

Dr. Cynthia Morton is Associate Curator of Botany at the Carnegie Museum of Natural History. 


\section{Curatorial Practice as Production of Visual and Spatial Knowledge}

\author{
Panelists Respond
}

\author{
Alison Langmead, Dan Byers, and Cynthia Morton
}

\section{Alison Langmead:}

Upon rereading our conversation, I was struck by a number of themes produced by our interactions, and I appreciate being given the opportunity here to reflect upon a few of them. The first such topic, and I think it was a central one, was our communal focus on all of the senses and their ability to produce meaning through a variety of experiences that extend beyond just sight. For me, this panel returned again and again to "Debating Sensory Knowledge," not just visual knowledge.

Cynthia was so very eloquent about the use of smell and touch in her presentation of her particular area of scientific research-citrus-and also in her approach to the Hall of Botany in the Carnegie Museum of Natural History. From cutting out pieces of paper marked ACGT and then rearranging them to better understand the code for DNA, to hoping to invite Whole Foods to participate in her museum interpretations in order to make plain the fundamental connection between plants, the livelihood of human beings, and the livelihood of the planet, her approach to incorporating more than sight into her curatorial practice was inspiring. Dan, too, focused on the whole-body experience of creating and then visiting a curated show in a museum. For me, his description of his rhetorical toolkit-comparison, juxtaposition, and durational accumulation of experience-delineated a fascinating combination of traditional academic stances toward art history (comparison and juxtaposition) with an important focus on the embodied experience of physically walking through an exhibition and developing a layered, sensory understanding of its meaningful choreography. It seems to me that Dan was asking us to see that it is through the eyes, the mind, and the body that meaning and knowledge can be constructed in the context of a museum. Terry also picked up on this theme when he discussed the ways in which curated exhibitions produce meaning as a network of interactions between the works of art, and then also the works of art and the visitor. Through contemporary innovations in the very form of the museum exhibition, curators are allowing for more than just abstract contemplation in their spaces; they are making room for a full-body process that can even take into account the past and the present of the museum itself.

As for myself, I also addressed this theme when I drew attention to the fact that we actually lose the ability to call on a number of our senses when we move into the digital realm. For example, where an old drawer of $35 \mathrm{~mm}$ slides took advantage of the affordances of physical objects and incorporated our own bodily movement into its information architecture (i.e., rifling through the slides with our fingers or moving through the history of art by physically moving through the collection), a digital image library cannot take advantage of those exact same affordances. We sit stationery at our computer, more or less, when we use them. We do not participate in a full-body choreography (for now-or perhaps forever). To move forward here, I argue, we have two main options. Either pretend that the digital space should be treated as a "virtual physical space" and attempt to map the world out here to the world in there through a process of mimicry and/or artificial recreation, or begin investigating the organizational principles native to the digital environment itself and use them to their best advantage. I, myself, am much more interested in the latter. Our digital world is not a blank slate. It deserves to be respected as an environment that is connected to, but not necessarily a replica of, our sensory environment. We have only scratched the surface of the possibilities inherent in the digital world we have constructed for ourselves.

The second theme is more directly related to our conversation about hardware and software as a metaphor for curation and the museum environment. It seems most salient to 
me, now that I have been able to reflect upon the ways in which our discussion unfolded, to bring in a brief mention of Platform Studies here. The scholars of our digital history who produce platform studies, such as Nick Montfort and Ian Bogost, argue that the distinctive line traditionally drawn between hardware and software is much more fuzzy than is habitually accepted. Just as software cannot be created without taking into consideration the ways in which the hardware wants to receive the information delivered for processing, modern hardware-certainly all hardware created commercially since the rise of the semiconductor-is likewise never created without considering the preexisting needs of contemporary software systems. What we have been producing for a while now are "platforms," perhaps to be understood also as digital ecosystems that are co-created by not just the hardware and the software, but also the entire cultural infrastructure surrounding the global digital world. There is no independent world for hardware or software to inhabit.

With this in mind, I would like to end my reflections with a comment on how Terry's thought-provoking metaphor might further inform our understanding of the relationship between curatorial practice and the physicality of the museum environment. By bringing in the hardware/software dichotomy, Terry did a great job of drawing our attention to the material reality of the museum infrastructure and the more abstracted, time-delimited work of the curator. Curatorial efforts could indeed fruitfully be seen as different software applications that run on the semi-fixed architectural hardware of the museum. Taking a cue from the Platform Studies scholars, however, we might be able to contextualize this analogy further, and perhaps even to draw in an additional theme present in the panel discussion. The practice of curation within the museum environment might instead be productively called a platform for the creation and expression of sensory knowledge. Indeed, Terry himself gestured to this idea when he noted that contemporary curatorial practice is very much engaged with tampering-or could we even say hacking?-the museum environment in order to transform the exhibitionary form itself. During the panel presentation, I argued that human beings might be considered as the "software" of this platform, but I stand now more sure that the co-creation of the "curatorial ecosystem" implies that such one-to-one correspondences are probably beside the point. Given how our conversation unfolded, I am inclined to believe that in the context of such metaphors, curation might most productively be compared to a complete platform for creating sensory experiences, out of which new knowledge and new meaning can be produced.

With this, I feel that I have returned to the central theme I have chosen to take away from the work of this panel. We engaged in a conversation about the implications of a "sensory knowledge" in which our eyes play only one part. It was a great honor to participate in this fascinating discussion, and I thank my fellow panel members for their time and expertise as well as Nicole for her skilled facilitation.

\section{Dan Byers:}

After so much time has passed since our stimulating conversation in the Carnegie Museum of Art theater (and I now find myself in Boston, at the ICA, staring out of my office across a sunny Boston Harbor as planes take off and land at Logan Airport), the questions and impressions I am left with are about big ideas and questions. I remember being struck, upon my first conversation with Cynthia, by the lack of visibility her important research received at the Natural History Museum. Why weren't the public programs and exhibitions of that museum derived from the research, and its attendant questions, generated by Cynthia and her scientist colleagues? It struck me how different this model was from the art museum, where it would be impossible to cleave the exhibitions from the interests, knowledge, and work of the museum's curators.

Upon further reflection, I think each model could learn from the other. And the lessons they would learn are big ones, about the public impact of culture, science, research, and the passions and knowledge of those who seek to define their parameters. Scientists who work 
in museums should be encouraged to make their research public, and to explore the forms and media by which this translation could occur. Its display and dissemination may very well create new pathways for research and new questions to ask. This is especially true for the research being conducted on questions and crises of the environment. This is labor that absolutely should be made public and drive the discourse around such urgent issues.

However there is also something sacrosanct about the research undertaken in museums and universities that may not find its way to the public for a very long time. It is vital that our society support this kind of work. And more and more, I believe art museums should also support their curators in this way. The public remains the most vital voice within any museum, and differentiates it from the academy. Knowledge and experience is shared, and in the sharing, culture is made. But as the emphasis is placed on spectacle, and on audience "development," "engagement," and "participation," (all concepts which are very easily bastardized today towards lowest common denominator ends), art museums could benefit from curators who have also spent long years in conversation with artists and researching in private. This program could happen simultaneously and develop into a more standard model.

As "sharing" has become not the means to the end, but rather the end itself, what might this model look like that withholds and nurtures and delays that moment of "sharing?" What if curators of contemporary art were encouraged to conduct studio visits, write, plan exhibitions, but then delay their actualization? How might private investigations flourish and become expansive, rather than elitist or myopic? Art is strange, and its making, curating, and interpretation is done by those who self-select because its ways and languages offer refuge and unique opportunities for understanding and communication.

Perhaps contemporary art and curating would benefit from more invisibility, less sharing (in the social media sense), and more delay before the robust act of generosity and democracy enacted by the meeting of art and its publics.

\section{Cynthia Morton:}

The organization of this panel as well as the revelation of ideas and information from the communication before and after the conference has changed Botany Hall and my perspective on the curatorial positions at Carnegie Institute.

Before this conference, Botany Hall badly needed renovations. I knew that removing the existing dioramas completely was not the answer because of their historical and educational value. The high cost of major renovations, as well as the artistic methods used in the creation of the dioramas, could never be replaced. Since this meeting, new LED lights have been installed in the dioramas and in the central area making the colors and the ability to see the details within the cases absolutely remarkable. New carpeting was installed and more hands-on activities were created to go along with the visual component of the Hall. Still more work needs to be done, however this has transformed Botany Hall. More people are using it daily and it has shown what a little renovation can do to make a space viable again.

Before the panel, I had a meeting with Dan Byers to discuss our jobs. In the twelve years I had been a curator at the Museum, I had never had this discussion before. I discovered that Dan spent about half of his time researching acquisitions and the other half of his time making the exhibition, working with artists, working with the development staff on writing proposals, individual donor cultivation, and fundraising. I did not realize that there was a real difference in our jobs. My job entails scientific research (maintaining the collections and conducting molecular studies), writing papers for peer review journals, applying for grants to limited funding sources, fulfilling outreach by teaching internally or externally, and working with education or exhibits to develop new botanical tools or exhibit experiences. As a curator, I am not involved in donor cultivation for research or exhibits. 
When I examined the files from the past, I noticed that the positions were not so different and only in the last several decades had there been a change.

Scientific research could be even more amazing at the museum but perhaps it needs a little renovation. I see great possibilities for our museums, especially using the new technologies that are emerging every day. I am grateful for the organization of this panel for it has made me see the potential in truly a new light. 
(cc) $\mathrm{BY}$

New articles in this journal are licensed under a Creative Commons Attribution 4.0 United States License.

\section{ULIS D-Sonk}

This journal is operated by the University Library System of the University of Pittsburgh as part of its D-Scribe Digital Publishing Program, and is co-sponsored by the University of Pittsburgh Press. 